\title{
Probe geometry and surface roughness effects in microscale impact testing of WC-Co
}

\author{
B.D. Beake ${ }^{1 *}$, L. Isern ${ }^{2}$, A.J. Harris ${ }^{1}$, J.L. Endrino ${ }^{2,3,4}$ \\ 1 Micro Materials Ltd, Willow House, Yale Business Village, Ellice Way, Wrexham, LL13, 7YL, UK
}

2 School of Aerospace, Transport and Manufacturing, Cranfield University, Bedford, MK43, 0AL, UK

3 Basque Center for Materials, Applications \& Nanostructures, UPV/EHU Science Park, Barrio Sarriena s/ n, 48940 Leioa, Spain

4 IKERBASQUE, Basque Foundation for Science, Maria Diaz de Haro 3, 48013 Bilbao, Spain

* Corresponding author. Tel: +44 1978 261615, Fax: +44 1978 356966. Email:

ben@micromaterials.co.uk

\begin{abstract}
Depth-sensing repetitive micro-impact tests have been performed on cemented carbide cutting tool inserts with spheroconical diamond probes with end radii of 8, 20 and $100 \mu \mathrm{m}$. Results were strongly dependent on probe radius and applied load. At higher load there was a transition to a faster damage rate marking the onset of more variability in rate and in the residual depth of the impact crater when using 8 and $20 \mu \mathrm{m}$ probes. SEM images show break-up of the WC skeleton at the periphery of the contact zone. Lower surface roughness slowed the initial damage rate at higher load but did not significantly influence the final crater depth. The loaddependent fatigue mechanism displayed by the cemented carbide also has implications for the study and optimisation of coatings when these are deposited.
\end{abstract}

Keywords:- impact, nanoindentation, fatigue, wear, hardmetal, cemented, carbide, cutting, tool, surface, damage. 


\section{Introduction}

In WC-Co hardmetals the combination of hard carbide and tough, energy-absorbing metallic binder results in a material with some of the best attributes of each phase. ${ }^{[1]}$ In many industrial applications, they are subjected to complex loading and determining the optimum grade can be challenging. Micro-scale mechanical tests and instrumented laboratory wear tests are used to obtain characterisation data under more controlled conditions than field trials. The tests can be used as a rapid screening tool for promising compositions and optimisation for durability in different mechanical contact situations. As they can easily and quickly be repeated, they provide a statistical overview of material performance. Contact damage of cemented carbides has been studied in indentation, ${ }^{[2-4]}$ cyclic contact fatigue, ${ }^{[5]}$ abrasion, ${ }^{[6]}$ scratch and erosion testing, ${ }^{[6-10]}$ micro-pillar compression and micro-cantilever bending tests. ${ }^{[1]}$ Zhang et al studied the indentation behaviour of different WC-10 wt.\% Co grades with a $5 \mathrm{~mm}$ spherical polycrystalline diamond indenter. ${ }^{[2-3]}$ Elasticity at low load developed into quasi-plasticity at higher load, with some micro-cracking evolving into a more brittle deformation at very high load with ring cracking then radial cracks appearing during unloading. Gee and co-workers studied the deformation of cemented carbides in repetitive scratch tests with small radius diamond probes. ${ }^{[8,10]}$ The major wear mechanisms involved the accumulation of damage, fracture and removal of WC grains which occurred by (i) fracture and fragmentation of the WC-grains, (ii) re-embedment of WC grain fragments into the Co binder (iii) cracking between grains and (iv) removal of fine material as debris. To study the resistance to cyclic loading, Küperfle and co-workers performed high cycle (to $10^{7}$ cycles) tests with a $5 \mathrm{~mm}$ radius silicon nitride indenter at forces to $2.8 \mathrm{kN}$ reporting that the samples with highest fracture toughness did not show the best fatigue resistance. ${ }^{[5]}$ In indentation tests at $1-5 \mathrm{kN}$ with $2 \mathrm{~mm}$ radius hardmetal pins, Góez and co-workers reported that the hardest grade tested (6 wt.\% Co) exhibited a single ring crack at $2.5 \mathrm{kN}$ and multiple ring cracks at $4 \mathrm{kN} .{ }^{[4]}$ In a grade with 10 
wt.\% Co fully developed cracking developed more gradually whilst the softest grade with 25 wt.\% Co showed only sink-in without cracking.

Accelerated nano- and micro-scale impact testing has been used in coating development to simulate cutting processes. Several studies have shown that the relative performance of coatings in metal cutting can be reliably replicated in the short-term tests. ${ }^{[12-15]}$ There are several potential advantages in testing at the nano-/micro-scale. For example, the tests are depth-sensing enabling the wear progression to be monitored throughout the test. Some of the differences between the new micro-impact test, nano-impact and conventional macro-scale impact testing are summarised in Table 1. In comparison to the ultra-sharp cube corner diamond indenters used in nano-impact testing, there is an intrinsic advantage in using blunter probes to study gradual fatigue processes. ${ }^{[4]}$

The micro-impact technique can also be used to evaluate the performance of bulk materials under repetitive impact. It has been used recently to evaluate the behaviour of three cemented carbide grades commonly used for oil and gas applications under micro-scale impact fatigue, two of them having similar hardness and toughness values, one with the presence of cubic phases. ${ }^{[16]}$ The highest resistance to impact fatigue was not achieved by the hardest and stiffest grade, nor the toughest grade, but for one with highest ratio of hardness $(H)$ to elastic modulus (E) and $H^{3} / E^{2}$. It is generally accepted for cemented carbides that high toughness is important in highly loaded mechanical contact, but the micro- and macro- tests above suggest that for optimum durability a suitable combination of high hardness and toughness is required.

In this study, the response of a cemented carbide grade used as a cutting tool insert to repetitive impact has been evaluated. The main aims of the current work include (i) studying influence of test probe geometry by performing tests with test probes of varying sharpness $(8,20,100$ $\mu \mathrm{m})$ over a range of impact forces $(0.1-3.0 \mathrm{~N})$ (ii) investigating the extent of influence of 
surface processing on the progression of impact damage by testing on commercial cemented carbide inserts, with and without an additional surface polishing step to reduce the influence of asperities which can act as stress-raisers (iii) improving our understanding of the deformation of cemented carbide insert used as substrate for coatings used in metal cutting where repetitive contact occurs (e.g. in high speed machining operations such as interrupted turning and end milling).

To produce hard wear-resistant coatings with greater durability under repetitive micro-impact, improved understanding of the role of substrate deformation on the overall coating-substrate system response is important to avoid premature failure. The response of the uncoated cemented carbide substrate can then be compared to previous data on coated systems with the same substrate to determine whether the substrate or coating fails first. ${ }^{[17,18]}$

Some impact tests with a $20 \mu \mathrm{m}$ end radius probe were performed under the same experimental conditions as in ref. ${ }^{[16]}$, allowing the results to be compared to those obtained on the grades tested in that study. The influence of mechanical properties such as $H^{3} / E^{2}$ on impact resistance is investigated.

Modifications to the experiment set up (acquisition of residual impact depth data) and data analysis (replotting data as impact depth increases to compare tests at different applied load) provided further insights into the repeatability of the impact damage progression and the influence of surface roughness on this.

\section{Materials and Methods}

\subsection{Characterisation}

Cemented carbide SPG422 cutting tool inserts were obtained from Sandvik. One of these (hereafter referred to as the polished insert) was mechanically polished by progressively 
polishing with 9, 6 and finally 1 micron diamond suspension to further reduce its surface roughness and whilst another (the as-received insert) was tested without further polishing. The inserts were characterised by XRD (Cu Ka radiation at $20 \mathrm{kV}$ with a Siemens D5005), SEM (TESCAN Vega3 SEM, backscattered electrons detector, $20 \mathrm{kV}$, working distance of $8.5 \mathrm{~mm}$ ) and EDX (Tescan Lyra3 FIB/SEM using an Oxford Instruments energy-dispersive x-ray spectroscope (EDS) and Aztec software). The areal surface roughness of the polished and asreceived samples was assessed by AFM measurement (Veeco NanoMan AFM) at $25 \mu \mathrm{m}$ x 25 $\mu \mathrm{m}$ scan area. Four measurements of the areal $R_{\mathrm{a}}$ surface roughness were determined at the $12.5 \times 12.5 \mu \mathrm{m}$ scale.

\subsection{Nanoindentation and Micro-impact}

Nanoindentation and micro-impact tests were performed with a NanoTest Vantage system (Micro Materials Ltd, Wrexham, UK). The instrument was fully ISO14577 calibrated for load, displacement, frame stiffness and indenter geometry. Nanoindentation was performed with a Berkovich diamond indenter whose area function (tip shape) was determined by indentation into a fused silica reference sample. On each sample there were 30 repeat indentations to 500 $\mathrm{mN}$ maximum load, loading at $25 \mathrm{mN} / \mathrm{s}$ with a $20 \mathrm{~s}$ hold at peak load before unloading at 100 $\mathrm{mN} / \mathrm{s}$. Hardness and reduced elastic modulus were determined from power-law fitting (Oliver and Pharr analysis) to the unloading curves. The elastic modulus and Poisson ratio of the diamond indenter were $1141 \mathrm{GPa}$ and 0.07 respectively. For the cemented carbides the reduced indentation moduli were converted to Elastic moduli assuming a Poisson ratio of 0.25.

For the micro-impact tests the $30 \mathrm{~N}$ high load head of the NanoTest Vantage was modified for impact testing as described previously. ${ }^{[17,18]}$ The loading head was actuated with a large electromagnet capable of pulling the probe $>50 \mu \mathrm{m}$ away from the sample surface. Three different test probe geometries were used as impact probes in this study: (i) a spheroconical 
diamond indenter with $90^{\circ}$ cone angle and calibrated end radius of $20 \mu \mathrm{m}$ (ii) a spheroconical diamond indenter with $90^{\circ}$ cone angle and calibrated end radius of $8 \mu \mathrm{m}$ and (iii) a diamond test probe with approximately $100 \mu \mathrm{m}$ end radius. The accelerating distance was set at $40 \mu \mathrm{m}$ in all the tests. The tests with the $20 \mu \mathrm{m}$ probe were performed at $1,1.5,2,2.5$ and $3 \mathrm{~N}$ on the polished insert and 2 and $3 \mathrm{~N}$ on the as-received insert. The test duration was $600 \mathrm{~s}$ with 1 impact every $4 \mathrm{~s}$, resulting in 150 impacts in total. There were three repeat tests at $3 \mathrm{~N}$ on the as-received insert. In all other tests with this probe there were five repeat impact tests at each load. In the micro-impact test there is a quasi-static indentation before the first actual impact. The on-load indentation depth associated with this is recorded and is used to confirm that the depth zero is measured correctly and the test did not impact in an anomalous region of the surface. The subsequent on-load depth was measured for each impact throughout the test and used to assess the progression of impact-induced damage through the test. In small scale tests where the load is applied throughout the test it is usually assumed that changes in the on-load depth (after correction for frame compliance but containing a contribution from elastic deformation) are generally closely correlated with changes in the residual wear depth. To check this, in the micro-impact tests the residual wear depth at the end of the test after load removal, i.e. with the elastic deformation component removed, were also recorded. Data were subsequently corrected for frame compliance. $300 \mathrm{~s} 75$ impact tests with the $8 \mu \mathrm{m}$ probe were performed on the as-received insert at $0.2,0.3,0.5$ and $1 \mathrm{~N}$. There were three repeats at each load. $300-1200 \mathrm{~s}$ tests with the $\sim 100 \mu \mathrm{m}$ probe were performed on the as-received insert at 1 2.5 N. The test conditions are summarised in Table 2.

Electron microscopy images of the impact craters were obtained using TESCAN Vega3 SEM and a TESCAN Lyra3 FIB/SEM with the secondary electrons detector, $20 \mathrm{kV}$, and at a working distance of $10 \mathrm{~mm}$. 


\section{Results and Discussion}

\subsection{Sample characterisation}

XRD confirmed that the inserts were essentially the same (Fig. 1(a)), with dominant WC peaks, very minor $\mathrm{Co} / \mathrm{Co}$ oxide peaks and no other refractory metals present (patterns compared with PDF-2 database of the ICDD). EDX compositions were WC-5 wt.\% Co on both samples. No traces of any other metals apart from W and Co were found. Grain size and morphology are virtually the same as confirmed by SEM imaging, as shown in Figure 1 (b,c). AFM images showed the presence of many fine scratches on the as-received insert and several deeper scratches. There were less of the fine scratches on the polished sample although some deeper scratches were still present. The $R_{\mathrm{a}}$ surface roughness was $(13.2 \pm 0.8) \mathrm{nm}$ on the as-received insert and $(9.9 \pm 0.7) \mathrm{nm}$ on polished insert.

The low wt.\% of the ductile Co binder in the cemented carbide cutting tool insert results in a WC-Co composite with high hardness and elastic modulus. The results of the nanoindentation tests at $500 \mathrm{mN}$ are summarised in Table 3 . The polished insert was slightly harder and stiffer with higher $H / E$ and $H^{3} / E^{2}$ than the as-received insert. The small mechanical differences found between the two samples in Table 1 arise from the surface polishing. The extra mechanical polishing process in the polished insert has slightly work hardened the surface and reduced the variability in the indentation tests, presumably by decreasing the surface roughness with a possible contribution from grain refinement at the surface. Studies where abrasion (as in polishing damage) have been simulated by scratch tests have shown a complex deformation mechanism involving WC grain fragmentation and re-embedding which can lead to some grain refinement at the surface. ${ }^{[6-10]}$ 


\subsection{General features of the load and probe dependent response to repetitive impact}

Illustrative SEM images of 1-3 N impact craters with the $20 \mu \mathrm{m}$ probe are shown for the polished insert in Figure 2 (a-g) and 2-3 $\mathrm{N}$ on the as-received insert in Figure 2 (h-i). Both samples showed clear load dependence in their impact response, with progressively greater damage at higher load. Pile-up (material uplift) and cracking was present around the impact craters on both samples throughout the load range, becoming increasingly severe in the higher load tests. The uplifted region extends far beyond the contact area, with ejected fine carbide debris further from the crater also observed (e.g. most clearly on the right hand side of fig. 2 $(b, c))$. Images at higher magnification (figure $2(f, g)$ ) show that at higher force there is a reduction in grain size of the $\mathrm{WC}$ in the centre of the impact crater and in the damage at the periphery due to WC grain fragmentation. Cracks form primarily between WC crystals with some WC cracking also observed.

Illustrative graphs of impact depth vs. number of impacts at each impact load are shown for the polished insert in figure 3 (a). Corresponding impact depth increases (i.e. setting depth after the first impact to zero) are shown in figure 3 (b). In addition to a strong dependence on applied load it is clear that the impact damage rate varies as the test progresses, particularly at higher load, which is discussed in more detail in section 3.5.

Convenient parameters for graphical illustration of the repeatability of the technique and its sensitivity to the applied load are:- (i) the on-load impact depth after the first impact, $\left(h_{1}\right)$; (ii) the on-load impact depth at the end of the test, $\left(h_{\mathrm{f}}\right)$ and (iii) the residual impact crater depth $\left(h_{\mathrm{r}}\right)$. The load dependence of these quantities is shown in Figure $4(\mathrm{a}-\mathrm{b}) . h_{1}$ was slightly higher and more scattered on the as-received insert. $2 \mathrm{~N}$ marks the transition point where there is higher wear through the test. Comparison of the final on- and off-load depths in figure 4 (a) shows good consistency with only a small load-dependent offset due to the elastic contribution. 
There was little difference in $h_{\mathrm{r}}$ between the samples. The tests show good repeatability in the mean depth after a single impact, particularly on the polished insert, and also in the mean depth at the end of the test when the transition to a faster wear process does not occur in any of the repeat tests at that load. In these cases the error bars are smaller than the size of the symbols in figure $4(a, b)$. When the higher damage rate was observed in some or all of the tests this produced greater variability in the residual depths, i.e. the test displays the stochastic response that is common in fracture-dominated processes. The transition typically occurred after around 60 to 120 impacts and was preceded by a sudden reduction in impact depth. Table 4 contrasts the impact fatigue damage rate in nm per impact before (over 40-60 impacts) and after (last 20 impacts) this transition.

Illustrative SEM images of impact craters from tests at $0.2-1 \mathrm{~N}$ with the sharper $8 \mu \mathrm{m}$ end radius probe on the as-received insert are shown in Figure 5. Pile-up around the impact site was observed at lowest load extending further from the crater at higher load. At 0.5 and $1.0 \mathrm{~N}$ the fragmentation at the periphery is much more extensive than at lower load. The impact depth data with the $8 \mu \mathrm{m}$ probe confirm the strong load dependence seen in the SEM images (figure 6). At 0.5 and $1 \mathrm{~N}$ there is a transition to a faster damage rate and depths move from spherical to the conical part of the indenter. With the $\sim 100 \mu \mathrm{m}$ probe the impacts were close to elastic. Optical microscopy revealed some surface damage but there was no well-defined impact crater. Under these conditions it was not possible to produce dramatic failure within the range of impact loads used. Some tests were run over $20 \mathrm{~min}$, these showed a very gradual fatigue process.

Previous micro-impact tests with this instrumentation have used spheroconical diamond probes with end radii in the range $17-20 \mu \mathrm{m} .{ }^{[17,18,23]}$ The smallest radius probe produced qualitatively similar impact behaviour to the $20 \mu \mathrm{m}$ probe but more rapidly and at a lower load. Higher 
plasticity in the tests with this probe result in pile-up under repetitive contact and cracking extending further outside the contact circle at higher load. The results of this study show that larger probes may not be particularly suitable for inducing sufficient damage for rapid testing of hard materials by micro-impact.

\subsection{Contrasting deformation in micro-impact and indentation contact}

The deformation in the micro-scale impact test can be contrasted to that observed in indentation contact at larger length scale. Fracture in larger scale tests on uncoated WC-Co initially proceeds by ring cracks followed by radial cracking. Zhang et al. studied the high load indentation behavior of different $\mathrm{WC}-10 \mathrm{wt}$.\% Co grades with a $5 \mathrm{~mm}$ spherical polycrystalline diamond indenter. At high load ring cracking was found, with radial cracking during unloading at yet higher load being the most extreme deformation observed. In contrast, in these microscale tests on the WC-5 wt.\% Co there is (i) pile-up at the periphery and (ii) the crack path is influenced by the local microstructure so that complete ring cracks were not observed before the onset of the more rapid wear process involving WC fragmentation. It can be concluded that the repetitive unloading-impact reloading at high contact pressure in the micro-impact test produces a more severe environment for crack propagation, with the damage morphology observed in the 2-3 $\mathrm{N}$ tests being more similar to that observed in high contact pressure repetitive micro-scale scratch tests with small radius diamond probes. ${ }^{[6-10]}$

\subsection{Factors causing pile-up at the periphery of the impact craters}

In the micro-impact tests, both samples tested showed similar behaviour with little differences in the residual wear depths and impact crater morphology between them. The impact damage with the $R=8 \mu \mathrm{m}$ and $R=20 \mu \mathrm{m}$ probes was strongly load-dependent. The SEM images (figs. 2 and 5) show considerable pile-up around the impact site after the repetitive impact tests. The ratio between the plastic work and the total elastic and plastic work done in indentation is a 
dimensionless plasticity index providing a convenient measure of the relative proportions of elastic and plastic deformation in an indentation test. The value of 0.67 reported in Table 3 is significantly below the value of 0.84 above which pile-up can occur with the Berkovich indenter geometry in non-work hardening materials. When spherical indenters are used the presence of pile-up or sink-in in non-work hardening materials can change during an indentation. This is due to the transition from purely elastic deformation at small depths (low $a / R)$ to plasticity-dominated deformation at larger depths. ${ }^{[19]}$ In WC-Co the strain hardening exponent is likely to be significantly higher ${ }^{[20,21]}$ than the 0.22 which marks the transition from pile-up to sink-in. ${ }^{[19]}$ Sink-in rather than pile-up was observed when WC-Co was indented with $R=5 \mathrm{~mm}$ polycrystalline diamond indenters up to $a / R$ of $\sim 0.15\left(\mathrm{a}=\right.$ contact radius $^{[2-3]}$ and in cyclic impact loading with $R=5 \mathrm{~mm} \mathrm{Si}_{3} \mathrm{~N}_{4}$ indenter. ${ }^{[5]}$ FEA by Taljat and Pharr has shown that increasing $h / R$ is qualitatively similar to increasing $E / \sigma_{\mathrm{y}}$. The pile-up observed around the impact crater in the repetitive impact tests with small radius probes appears to be a consequence of the higher $a / R(\sim 0.3-0.5)$ in the test with the progressive damage from the repetitive contact moving the contact further away from elastic, which may be a function of indenter radius. Rhee et al noted that the deformation in an indentation test is a function of the radius of the indenter, with larger radii indenters producing more brittle deformation and smaller radii indenters more plasticity. ${ }^{[22]}$ In these repetitive tests however, the greater plasticity (and pile-up) ultimately results in the break-up of the $\mathrm{WC}$ structure and a transition to a more aggressive wear regime. In a Hertzian (elastic) stress field the maximum tensile stress is at the circle of contact and falls off dramatically below the top surface. ${ }^{[22]}$ Figures 2 and 5 show that the region with greatest cracking extends significantly beyond the Hertzian contact radius, as has been observed in cyclic impact loading with a $5 \mathrm{~mm}$ radius $\mathrm{Si}_{3} \mathrm{~N}_{4}$ indenter ${ }^{[5]}$ and in micro-impact tests on other cemented carbides [16]. This is considered to be due plasticity resulting in pile-up moving the peak radial tensile stresses outward. In high-cycle fatigue studies the deformation proceeds by 
slow formation of a closed ring crack and then slow growth of radial cracks. ${ }^{[5]}$ In the microimpact after the partial cracking at the edge of the impact crater the fragmentation of the WC and removal of Co binder result in a more severe wear process more akin to that found in microscratch/abrasion tests which is not seen with the larger $(5 \mathrm{~mm})$ probes in the higher force and higher-cycle fatigue tests where the cracks slowly extend outwards.

\subsection{Influence of surface processing on changing wear rate during the test}

To study the behaviour with the $20 \mu \mathrm{m}$ probe in more detail the increase in impact depth through the test (i.e. after setting the impact depth to zero after impact 1) is shown in fig. 3 (b). At the three lowest forces there can be a shallow minimum in the on-load impact depth after $\sim 75$ impacts which is considered to reflect work hardening and greater elastic recovery. Similar behaviour was reported in nanoindentation fatigue studies where multi-cycling indentation tests on a WC-35 wt.\% Co with a Berkovich indenter at $25-200 \mathrm{mN}$ exhibited a maximum depth after $\sim 50$ cycles before gradually decreasing throughout the rest of the 100 -cycle test. ${ }^{[24]}$ At higher load there was more variability in the tests with some difference in how the rate of impact wear changed through the test on the polished insert and the as-received insert, as illustrated at $3 \mathrm{~N}$ in Figure $7(\mathrm{a}, \mathrm{b})$. The damage rate on the polished insert was lower prior to the transition to the faster damage rate. On the as-received insert the there was a more gradual transition to faster wear although the rate of increase is less pronounced, so that the residual depth at the end of the test was almost the same for both samples. The data in Table 4(a,b) show the same trends at 2 and $3 \mathrm{~N}$. A combination of topographical and mechanical factors are likely to be responsible for the observed differences. The slightly greater and more variable $h_{1}$ on the as-received insert is consistent its lower elastic modulus and higher surface roughness. The asperities on the higher surface roughness the as-received insert can act as stress raisers to initiate (further) damage more rapidly than on the smoother polished insert. ${ }^{[25]}$ The additional 
polishing also slightly altered the surface mechanical properties resulting in small increases in hardness, elastic modulus, $H / E$ and $H^{3} / E^{2}$. Higher $H^{3} / E^{2}$ can result in more elastic contact resulting in improved wear resistance at lower load, ${ }^{[26-27]}$ and improved resistance to fracture initiation. However, resistance to crack propagation (damage tolerance) may require different properties. As wear progresses and/or in more severe tests, there may be a requirement to dissipate energy through plastic deformation and/or micro-fracture processes which can minimise strain accumulation.

\subsection{Comparison to previously published work on oil and gas grades}

The impact resistance of the cutting tool grade tested in this study after polishing can be directly compared to highly polished samples of grades used in oil and gas drilling applications that were studied previously with a $20 \mu \mathrm{m}$ probe under the same test conditions. ${ }^{[16]}$ Since cemented carbides show a smaller-is-stronger size effect in hardness ${ }^{[11,28]}$ the indentation peak load was the same in ref. ${ }^{[16]}$ and the current study. In that study two cemented carbide grades with 5-7 wt. $\%$ of mixed Co-Ni binder with $H \sim 22-23 \mathrm{GPa}$ and $H^{3} / E^{2}=0.25-0.33 \mathrm{GPa}$ showed better resistance. Another grade with Co binder and $H=18.9 \mathrm{GPa}, H^{3} / E^{2}=0.016 \mathrm{GPa}$ performed poorly showing dramatic WC fragmentation outside the impact crater from $2 \mathrm{~N}$. The polished WC-Co insert studied here showed slightly better impact resistance than this but it was significantly worse than the grades with Co-Ni binder, consistent with its mechanical properties $\left(H=20.6 \mathrm{GPa}, H^{3} / E^{2}=0.020 \mathrm{GPa}\right)$ being intermediate between these grades (i.e. the present results support the conclusion from ref 16 that increasing $H^{3} / E^{2}$ correlates with improved impact resistance, at least over the range studied to date).

\subsection{Implications for substrate processing for coating durability}

The load-dependent fatigue mechanisms displayed by the cutting tool substrate have implications for the study and optimisation of coatings on these substrates. Coating fracture in 
over-load tests commonly proceeds by substrate elastic and plastic deformation resulting in bending stresses. The present results suggest that in repetitive impact of a coating deposited on hardmetals substrate fatigue needs to be considered as a potential precursor of coating damage. Deposition of novel coatings on smoother and/or more impact resistant grades of cemented carbide substrate with higher $H^{3} / E^{2}$ may be beneficial for the optimisation of their behaviour for cutting tests such as high-speed milling where they will be exposed to repetitive impact.

\section{Conclusions}

Impact resistance of the WC-Co inserts was strongly load and probe geometry dependent. In higher load tests with 8 and $20 \mu \mathrm{m}$ end radius probes there was a transition to a faster damage rate associated with fragmentation of the WC crystals. An additional surface polishing step before testing influenced the progression of impact wear through the test by reducing asperities that could act as stress raisers to initiate further damage more rapidly and in producing a slightly harder and initially more wear-resistant surface. Comparison with cemented carbide grades used in oil and gas applications shows that grades with higher $H^{3} / E^{2}$ have enhanced impact resistance. The load-dependent fatigue mechanism displayed by the cemented carbide also has implications for the study and optimisation of coated cutting tools. In applications where mechanical tools and components are exposed to repetitive impact in operation their performance may be improved by the use of smoother and/or more impact resistant grades of cemented carbide substrate with higher $H^{3} / E^{2}$. 


\section{Acknowledgements}

Funding to develop the novel micro-impact test technique through the Innovate UK Project No: 132369 - "Nano-to Micro-Impact Testing: An in-situ test for UK SEAC sector" is gratefully acknowledged. C. Kimpton and X.W. Liu (both Cranfield University) are both acknowledged for their technical assistance with the SEM imaging and L. Bergdoll (Micro Materials) is acknowledged for his help with some of the impact testing. S. Kimpton (Cranfield University) is acknowledged for performing the AFM measurements.

\section{References}

1. Roebuck, B.; Almond, E.A. Deformation and fracture processes and the physical metallurgy of WC-Co hardmetals. Int. Mater. Rev. 1988, 33, 90-110. DOI:10.1179/1988.33.1.90.

2. Zhang, H.; Fang, Z.Z. Characterisation of quasi-plastic deformation of WC-Co composite using Hertzian indentation technique, Int. J. Refract. Met. Hard Mater. 2008, 26, 106-114. DOI: 10.1016/j.ijrmhm.2007.02.002.

3. Zhang, H.; Fang, Z.Z.; Belnap, J.D. Quasi-plastic deformation of WC-Co composites loaded with a spherical indenter, Metall. Mater. Trans. A 2007, 38A, 552-561. DOI: 10.1007/s11661-006-9036-y.

4. Góez, A.; Coureaux, D.; Ingebrand, A.; Reig, B.; Tarrés, E.; Mestra, A.; Mateo, A.; Jiménez-piqué, E.; Llanes, L. Contact damage and residual strength in hardmetals. Int. J. Refract. Met. Hard Mater. 2012, 30, 121-127. DOI: 10.1016/j.ijrmhm.2011.07.013.

5. Küpferle, J.; Röttger, A.; Theisen, W. Fatigue and surface spalling of cemented carbides under cyclic impact loading - Evaluation of the mechanical properties with respect to 
microstructural processes. Wear 2017, 390-391, 33-40. DOI: 10.1016/j.wear.2017.07.002.

6. Gee, M.G.; Gant, A.; Roebuck, B. Wear mechanisms in abrasion and erosion of WC/Co and related hardmetals. Wear 2007, 263, 137-148. DOI: 10.1016/j.wear.2006.12.046.

7. M. Gee, M.; K. Mingard, K.; Roebuck, B. Application of EBSD to the evaluation of plastic deformation in the mechanical testing of WC/Co hardmetal. Int. J. Refract. Met. Hard Mater. 2009, 27, 300-312. DOI: 10.1016/j.ijrmhm.2008.09.003.

8. M. Gee, M.; K. Mingard, K.; Nunn, J.; Roebuck, B.; Gant, A. In situ scratch testing and abrasion simulation of WC/Co. Int. J. Refract. Met. Hard Mater. 2017, 62, 192-201. DOI: 10.1016/j.ijrmhm.2016.06.004.

9. Gant, A.J.; Nunn, J.W.; Gee, M.G.; Gorman, D.; Gohil, D.D.; Orkney, L.P. New perspectives in hardmetal abrasion simulation, Wear 2017, 376-377, 2-14. DOI: 10.1016/j.wear.2017.01.038.

10. Zuñega, J.C.P..; Gee, M.G.; Wood, R.J.K.; Walker, J. Scratch testing of WC/Co hardmetals. Tribol. Int. 2012, 54, 77-86. DOI: 10.1016/j.triboint.2012.02.027.

11. Naughton-Duszová, A.; Csanádi, T.; Sedlák, R.; Hvizdoš, P.; Dusza, J. Small-scale mechanical testing of cemented carbides from the micro- to the nano-level: a review. Metals 2019, 9, 502 (25pp). DOI: 10.3390/met9050502.

12. Fox-Rabinovich, G.S.; Yamamoto, K.; Beake, B.D.; Kovalev, A.I.; Aguirre, M.H.; Veldhuis, S.C.; Dosbaeva, G.K.; Wainstein, D.L.; Biksa A.; Rashkovskiy, A.I. Emergent behavior of nano-multilayered coatings during dry high speed machining of hardened tool steels, Surf. Coat. Technol. 2010, 204, 3425-3435. DOI: 10.1016/ j.surcoat.2010.04.002. 
13. Bouzakis, K.-D.; Klocke, F.; Skordaris, G.; Bouzakis, E.; Geradis, S.; Katirtzoglou G.; Makrimallakis, S. Influence of dry micro-blasting grain quality on wear behaviour of TiAlN coated tools, Wear 2011, 271, 783-791. DOI: 10.1016/j.wear.2011.03.010.

14. Fox-Rabinovich, G.S.; Beake, B.D.; Veldhuis, S.C.; Endrino, J.L.; Parkinson, R.; Shuster, L.S.; Migranov, M.S. Impact of mechanical properties measured at room and elevated temperatures on wear resistance of cutting tools with TiAlN and $\mathrm{AlCrN}$ coatings, Surf. Coat. Technol. 2006, 200, 5738-5742. DOI: 10.1016/ j.surcoat.2005.08.132.

15. Beake, B.D.; J.F. Smith, J.F.; Gray, A.; Fox-Rabinovich, G.S.; Veldhuis, S.C.; Endrino, J.L. Investigating the correlation between nano-impact fracture resistance and hardness/modulus ratio from nanoindentation at $25-500^{\circ} \mathrm{C}$ and the fracture resistance and lifetime of cutting tools with $\mathrm{Ti}_{1-\mathrm{x}} \mathrm{Al}_{\mathrm{x}} \mathrm{N}(\mathrm{x}=0.5$ and 0.67$)$ PVD coatings in milling operations, Surf. Coat. Technol. 2007, 201, 4585-4593. DOI: 10.1016/ j.surcoat.2006.009.118.

16. Cinca, N.; Beake, B.D.; Harris, A.J.; Tarrés, E. Micro-scale impact testing on cemented carbide, Int. J. Refract. Met. Hard Mater. 2019, 84, 105045. DOI: 10.1016/j.ijrmhm.2019.105045.

17. Beake, B.D.; Isern, L.; Endrino, J.L.; Fox-Rabinovich, G.S. Micro-impact testing of AlTiN and TiAlCrN coatings, Wear 2019, 418-419, 102-110. DOI: 10.1016/j.wear.2018.11.010.

18. Beake, B.D.; Bird, A.; Isern, L.; Endrino, J.L.; Jiang, F. Elevated temperature microimpact testing of TiAlSiN coatings produced by physical vapour deposition, Thin Solid Films (in press, available online 8 June 2019). DOI: 10.1016/j.tsf.2019.06.008. 
19. Taljat, B.; Pharr, G.M. Development of pile-up during spherical indentation of elasticplastic solids, Int. J. Sol. Struct. 2004, 41, 3891-3904. DOI: 10.1016/j.ijsolstr.2004.02.033.

20. Klüsner, T.; Marsoner, S.; Ebner, R.; Pippan, R.; J. Glätzle, J.; Püschel, A. Effect of microstructure on fatigue properties of WC-Co hard metals, Proc. Eng. 2010, 2, 20012010. DOI: 10.1016/j.proeng.2010.03.215.

21. Hazell, P.J.; Appleby-Thomas, G.J.; Herlaar, K.; Painter, J. Inelastic deformation and failure of tungsten carbide under ballistic-loading conditions. Mater. Sci. Eng. A 2010, 527, 7638-7645. DOI: 10.1016/j.msea.2010.08.024.

22. Rhee, Y.-W.; Kim, H.-W.; Deng, Y.; Lawn, B.R. Brittle fracture versus quasi-plasticity in ceramics: a simple predictive index. J. Am. Ceram. Soc. 2001, 84, 561-565. DOI: 10.1111/j.1151-2916.2001.tb00698.x.

23. Beake, B.D.; Liskiewicz, T.W.; Bird, A.; Shi, X. Micro-scale impact testing - A new approach to studying fatigue resistance in hard carbon coatings, Tribol. Int. (in press, available online 11 April 2019.) DOI: 10.1016/j.triboint.2019.04.016.

24. Duszová, A.; Hvizdo, P.; Major, Ł.; Dusza, J.; J. Morgiel, J. Indentation fatigue of WC - Co cemented carbides. Int. J. Refract. Met. Hard Mater. 2013, 41, 229-235. DOI: 10.1016/j.ijrmhm.2013.04.006.

25. Steiner, L.; Bouvier, V.; May, U.; Hegadekette, V.; Huber, N. Modelling of unlubricated oscillating sliding wear of DLC-coatings considering surface topography, oxidation and graphitisation. Wear 2010, 268, 1184-1194. DOI: 10.1016/j.wear.2009.12.026.

26. Hassani, S.; Bielawski, M.;Beres, W.; Martinu, L.; Balazinski M.; Klemberg-Sapieha, J.E. Predictive tools for the design of erosion resistant coatings. Surf. Coat. Technol. 2008, 203, 204-210. DOI: 10.1016/j.surcoat.2008.08.050. 
27. Bousser, E.; Benkahoul, M.; Martinu, L.; Klemberg-Sapieha, J.E. Effect of microstructure on the erosion resistance of Cr-Si-N coatings. Surf. Coat. Technol. 2008, 203, 776-780. DOI: 10.1016/j.surcoat.2008.08.012.

28. Nabarro, F.R.N.; Shrivastava, S.; Luyckx, S.B. The size effect in microindentation. Philos. Mag. 2006, 86, 4173-4180. DOI: 10.1080/14786430600577910 
Table 1 Comparison between different types of impact test*

\begin{tabular}{|c|c|c|c|}
\hline & Nano-impact & Micro-impact & Macro-impact \\
\hline Depth-sensing & $\mathrm{Y}$ & $\mathrm{Y}$ & $\mathrm{N}$ \\
\hline Accurate time-to-failure & $\mathrm{Y}$ & $\mathrm{Y}$ & $\mathrm{N}$ \\
\hline Test duration & $5-10 \mathrm{~min}$ & $5-10 \mathrm{~min}$ & Extended duration \\
\hline Test probe material & Diamond & Diamond & WC-Co \\
\hline Test probe radius & $\sim 100 \mathrm{~nm}$ & $5-100 \mu \mathrm{m}$ & $0.5-3 \mathrm{~mm}$ \\
\hline Automatic scheduling of & $\mathrm{Y}$ & $\mathrm{Y}$ & $\mathrm{N}$ \\
multiple tests & & & $>>100$ \\
\hline Applied load (N) & $0.001-0.2$ & & \\
\hline
\end{tabular}

* Conditions shown are typical but all three types of tests can be run with different experimental parameters.

Table 2 Micro-impact test matrix

\begin{tabular}{|c|c|c|c|c|c|}
\hline $\begin{array}{c}\text { Test probe } \\
\text { radius }(\mu \mathrm{m})\end{array}$ & $\begin{array}{c}\text { Applied load } \\
(\mathrm{N}) \text { in tests } \\
\text { on as } \\
\text { received } \\
\text { insert }\end{array}$ & $\begin{array}{c}\text { Applied } \\
\text { load }(\mathrm{N}) \text { in } \\
\text { tests on } \\
\text { polished } \\
\text { insert }\end{array}$ & $\begin{array}{c}\text { Accelerating } \\
\text { distance } \\
(\mu \mathrm{m})\end{array}$ & $\begin{array}{c}\text { Test } \\
\text { duration }(\mathrm{s})\end{array}$ & $\begin{array}{c}\text { Repetitions } \\
\text { at each load }\end{array}$ \\
\hline 8 & $\begin{array}{c}0.2,0.3,0.5, \\
1.0\end{array}$ & - & 40 & 300 & 5 \\
\hline 20 & $2.0,3.0$ & $1.0,1.5,2.0$, & 40 & 600 & $5^{a}$ \\
\hline 100 & $1.0,1.5,2.0$, & $2.5,3.0$ & & 300 and & 3 or $^{b}$ \\
& 2.5 & - & 40 & 1200 & \\
\hline
\end{tabular}


$a 3$ repeats at $3 \mathrm{~N}$ on as-received. $b 5300$ s repeats at 1.0 and $1.5 \mathrm{~N} ; 3 \times 300$ and $3 \times 1200$ repeats at $2.0,2.5 \mathrm{~N}$.

Table 3 Surface mechanical properties from nanoindentation at $500 \mathbf{~ m N}$

\begin{tabular}{|c|c|c|}
\hline & Polished insert $^{\text {a }}$ & As-received insert \\
\hline Hardness $(\mathrm{GPa})$ & $20.6 \pm 1.0$ & $19.1 \pm 1.2$ \\
\hline Elastic modulus $(\mathrm{GPa})$ & $670 \pm 23$ & 0.030 \\
\hline$H / E$ & 0.031 & 0.017 \\
\hline$H^{3} / E^{2}(\mathrm{GPa})$ & 0.020 & $149 \pm 8$ \\
\hline Plastic work $(n J)$ & $141 \pm 6$ & $62 \pm 1$ \\
\hline Elastic work $(n J)$ & $63 \pm 1$ & $0.70 \pm 0.01$ \\
\hline Plasticity index $b$ & $0.69 \pm 0.01$ & \\
\hline
\end{tabular}

$a$ The polished insert has lower surface roughness. $b$ Plasticity index $=$ plastic work/total work. 
Table 4 Impact damage rate \#

(a) with $R=20 \mu \mathrm{m}$ probe on the polished insert

\begin{tabular}{|c|c|c|c|c|c|}
\hline & $1.0 \mathrm{~N}$ & $1.5 \mathrm{~N}$ & $2.0 \mathrm{~N}$ & $2.5 \mathrm{~N}$ & $3.0 \mathrm{~N}$ \\
\hline $\begin{array}{c}\text { Over 40-60 } \\
\text { impacts }\end{array}$ & $0.2 \pm 0.8$ & $-0.5 \pm 0.3$ & $0.2 \pm 1.0$ & $1.4 \pm 0.6$ & $2.2 \pm 1.1$ \\
\hline $\begin{array}{c}\text { Over last 20 } \\
\text { impacts }\end{array}$ & $3.1 \pm 1.0$ & $2.9 \pm 0.9$ & $13 \pm 12$ & $34 \pm 20$ & $44 \pm 24$ \\
\hline
\end{tabular}

(b) with $R=20 \mu \mathrm{m}$ probe on the as-received insert

\begin{tabular}{|c|c|c|}
\hline & $2.0 \mathrm{~N}$ & $3.0 \mathrm{~N}$ \\
\hline Over 40-60 impacts & $2.5 \pm 1.2$ & $14 \pm 7$ \\
\hline Over last 20 impacts & $4.6 \pm 0.7$ & $62 \pm 24$ \\
\hline
\end{tabular}

(c) with $R=8 \mu \mathrm{m}$ probe on the as-received insert

\begin{tabular}{|c|c|c|c|c|}
\hline & $0.2 \mathrm{~N}$ & $0.3 \mathrm{~N}$ & $0.5 \mathrm{~N}$ & $1.0 \mathrm{~N}$ \\
\hline Over last 10 impacts & $1.0 \pm 0.2$ & $4.8 \pm 1.5$ & $67 \pm 33$ & $59 \pm 14$ \\
\hline
\end{tabular}

${ }^{\#}$ Impact damage rate defined as depth increase in $\mathrm{nm}$ per impact 


\section{Figure Captions}

1. XRD spectra (a) and back-scattered mode SEM images of (b) as-received and (c) polished inserts at $\mathrm{x} 25000$ original magnification.

2. SEM images of impact craters with the $20 \mu \mathrm{m}$ probe. (a-g) on the polished insert:- (a) $1 \mathrm{~N}$; (b) $1.5 \mathrm{~N}$; (c) $2 \mathrm{~N}$; (d) $2.5 \mathrm{~N}$; (e) $3 \mathrm{~N}$. (a-e) at x4000 original magnification. (f) $1 \mathrm{~N}$ test at original magnification $\mathrm{x} 15000$ and (g) $3 \mathrm{~N}$ test at $\mathrm{x} 10600$ original magnification. (h-i) on the as-received insert:- (h) $2 \mathrm{~N}$; (i) $3 \mathrm{~N}$. (h-i) at x4000 original magnification.

3. Evolution of (a) impact depth and (b) increase in impact depth, with number of impacts with $20 \mu \mathrm{m}$ probe on the polished insert.

4. Load dependence of impact parameters in tests with the $20 \mu \mathrm{m}$ probe on (a) the polished insert (b) the as-received insert (c) residual wear depth.

5. SEM images of impact craters with the $8 \mu \mathrm{m}$ probe on the as-received insert at $\mathrm{x} 4000$ original magnification. (a) $0.2 \mathrm{~N}$; (b) $0.3 \mathrm{~N}$; (c) $0.5 \mathrm{~N}$; (d) $1 \mathrm{~N}$.

6. Evolution of (a) impact depth and (b) increase in impact depth with number of impacts with $8 \mu \mathrm{m}$ probe on the as-received insert.

7. Evolution of impact depth with number of impacts with $20 \mu \mathrm{m}$ probe in repeat tests at $3 \mathrm{~N}$ on (a) the polished insert (b) the as-received insert. 


\section{Figures}
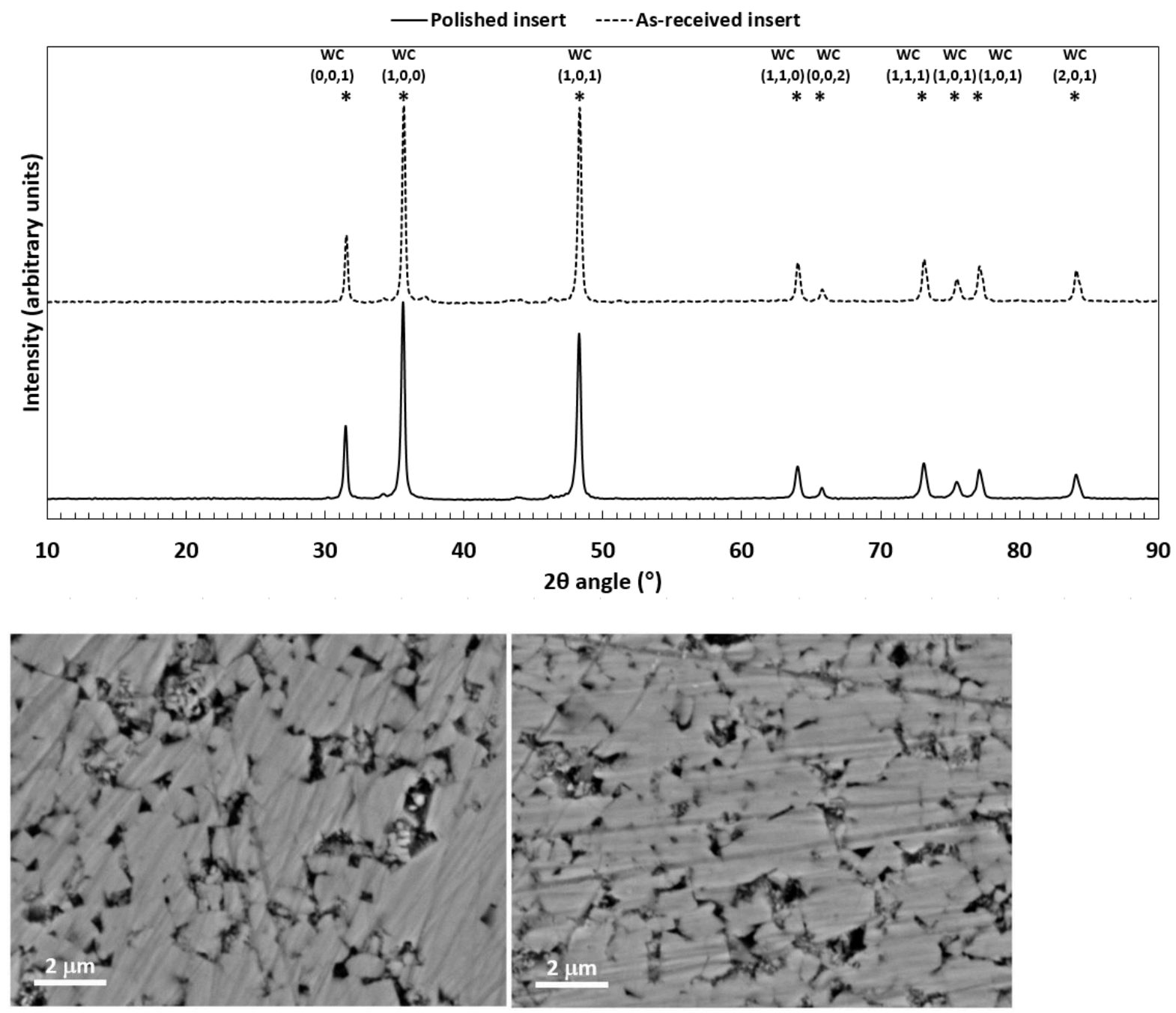

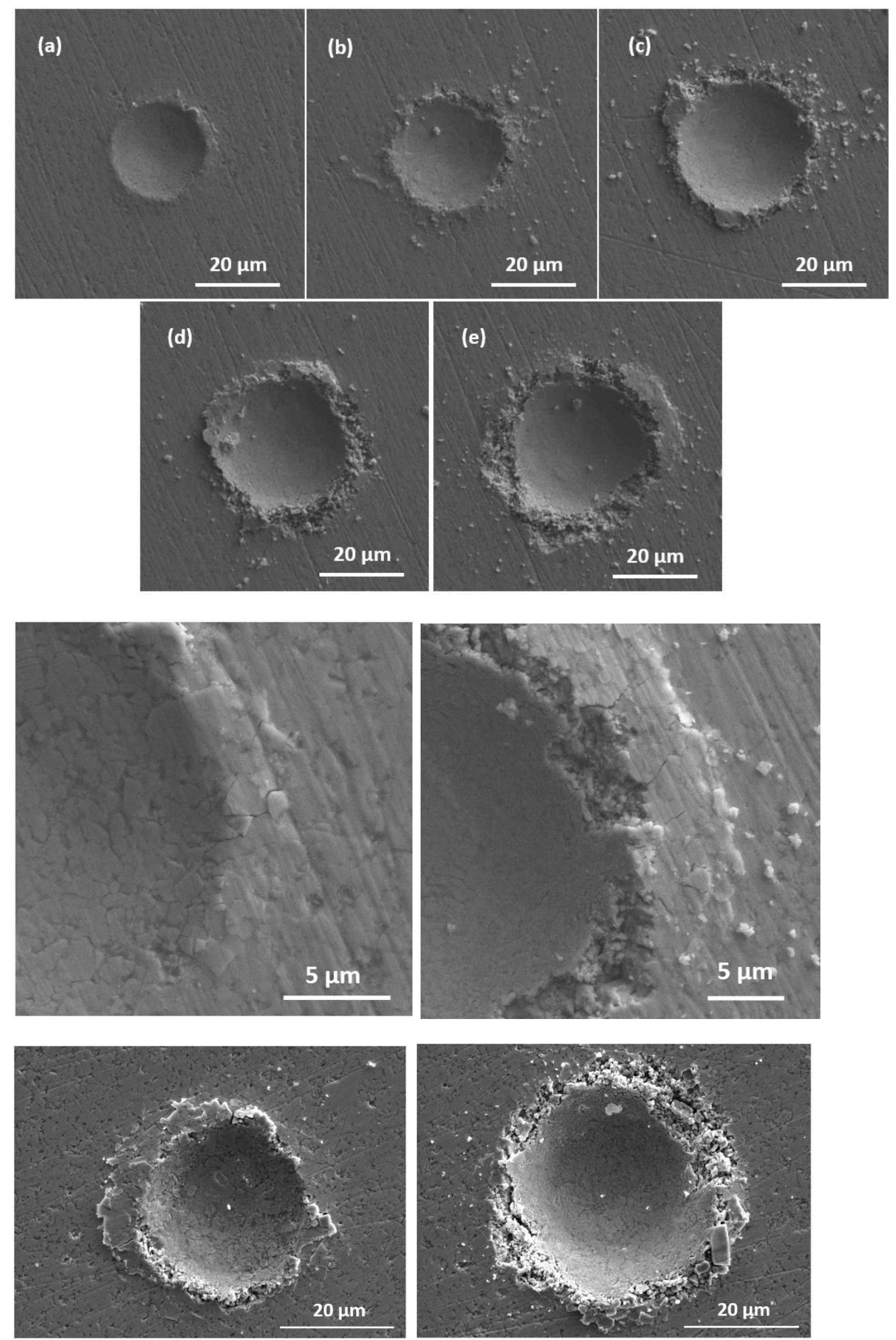

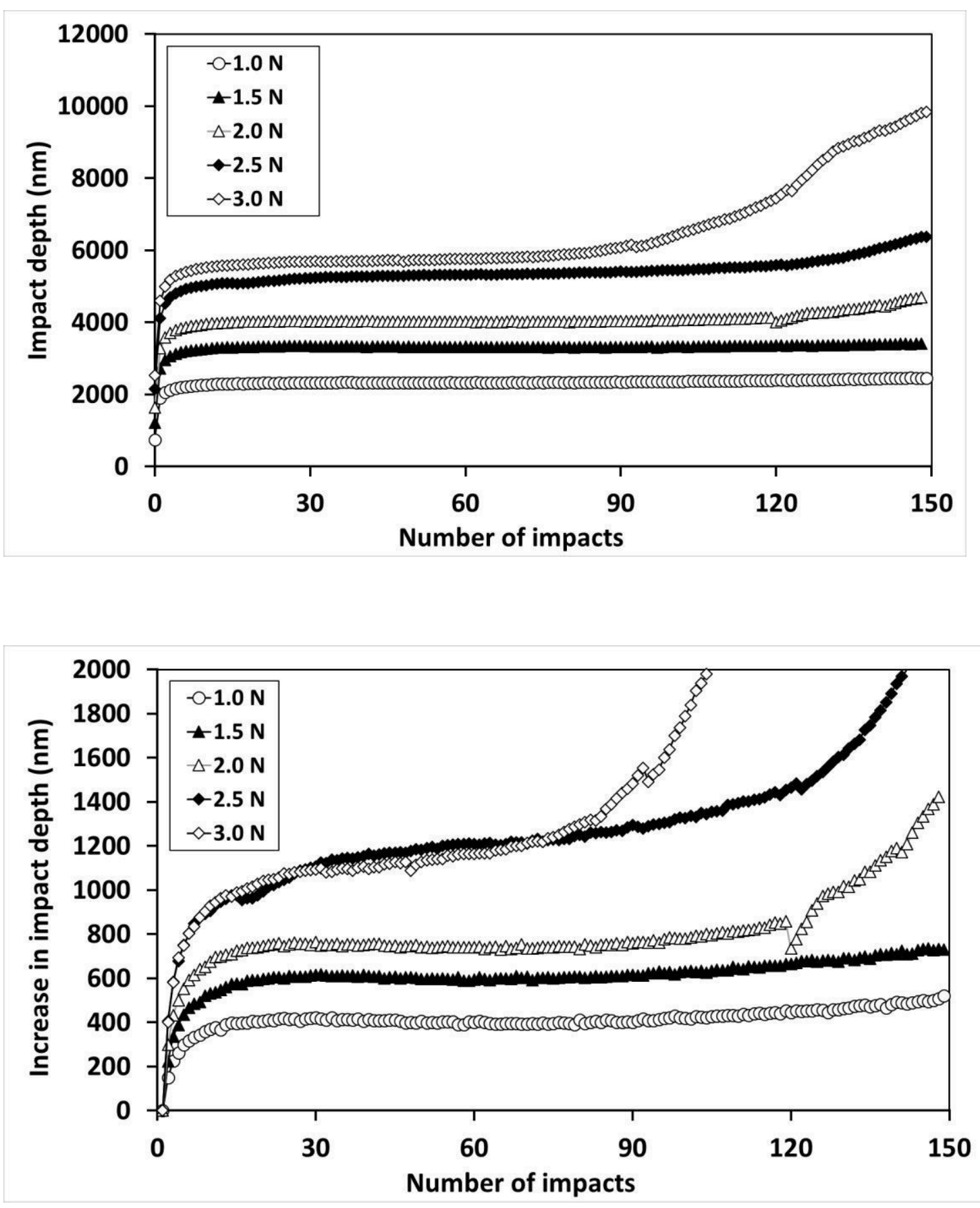

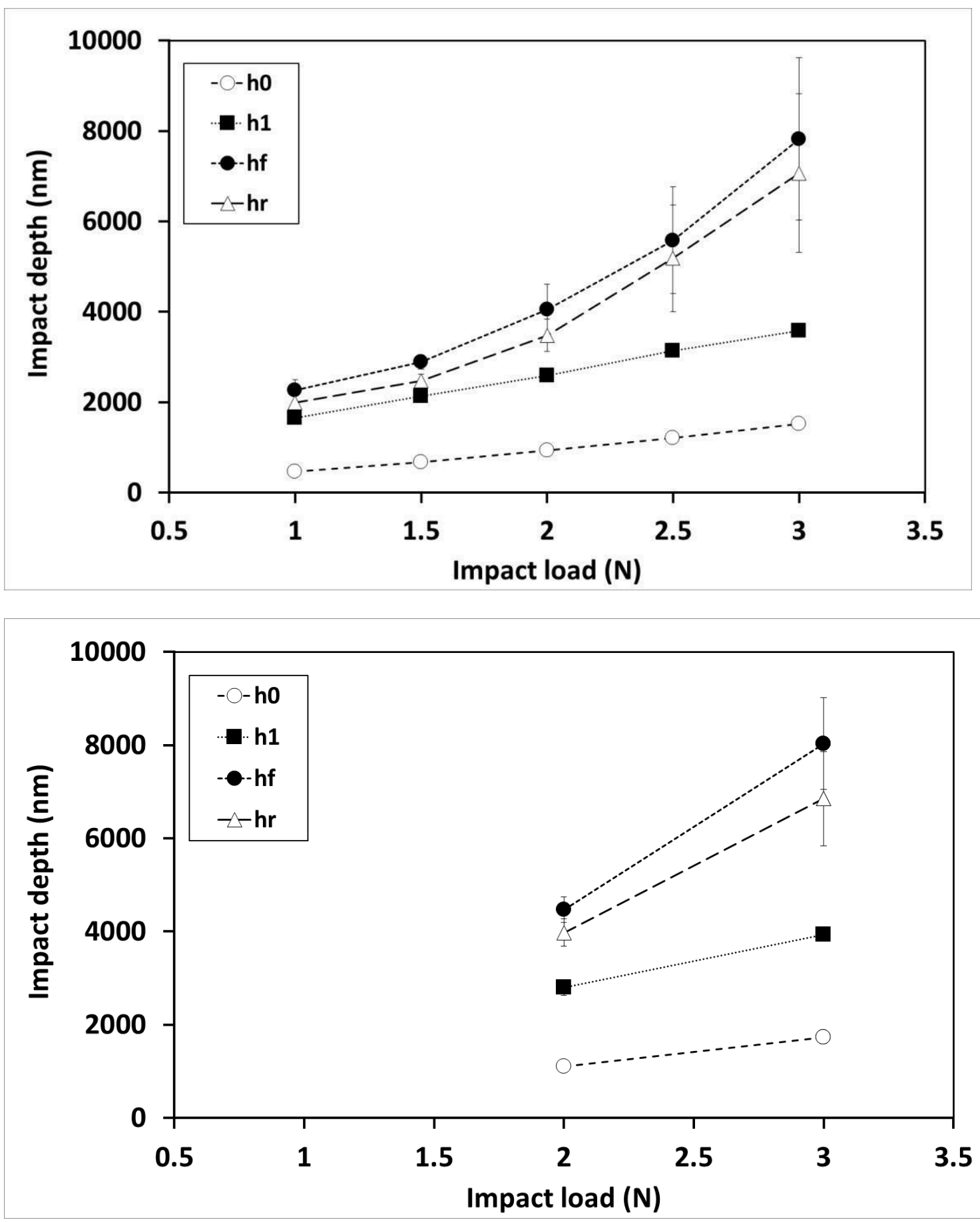

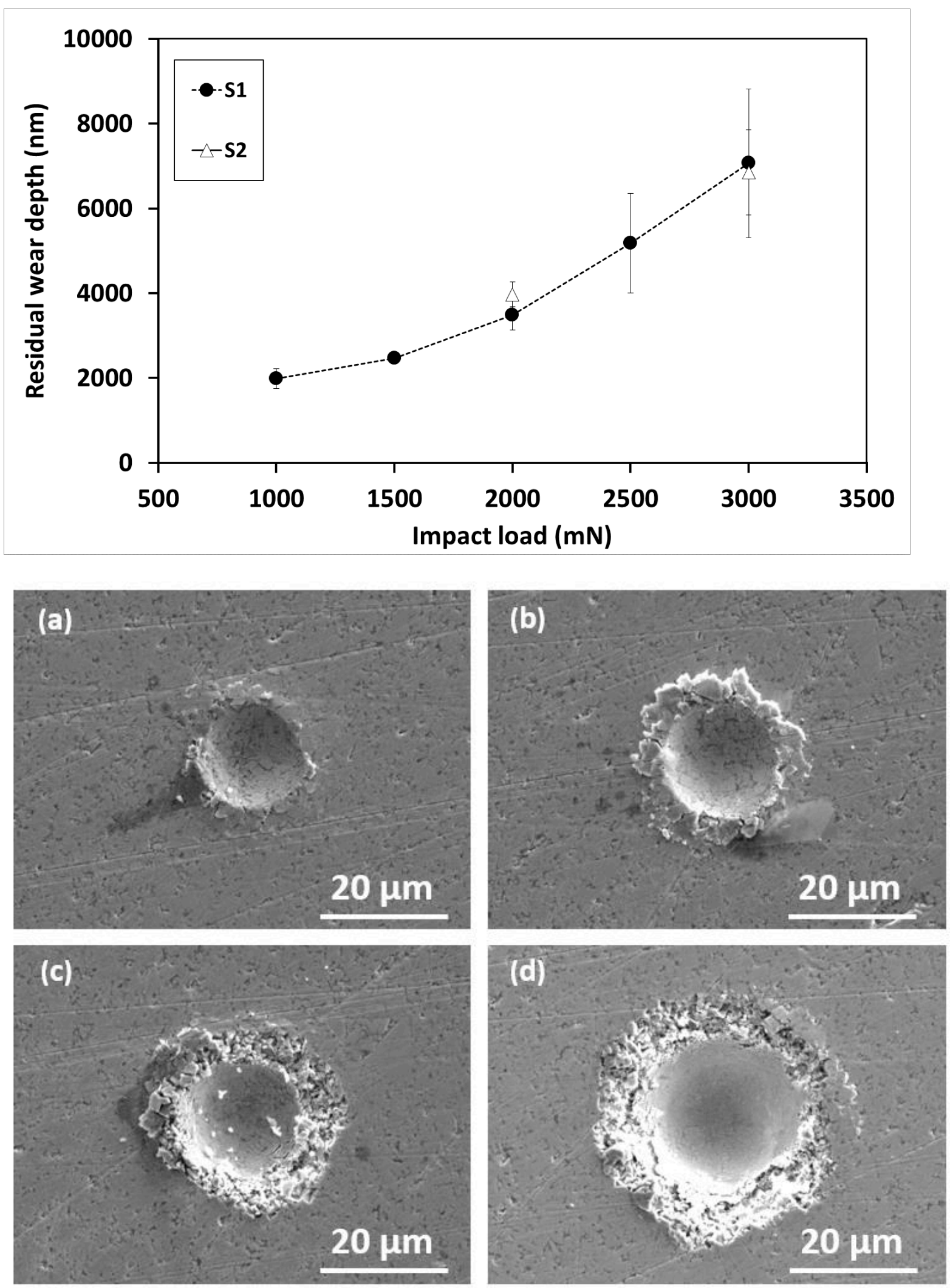

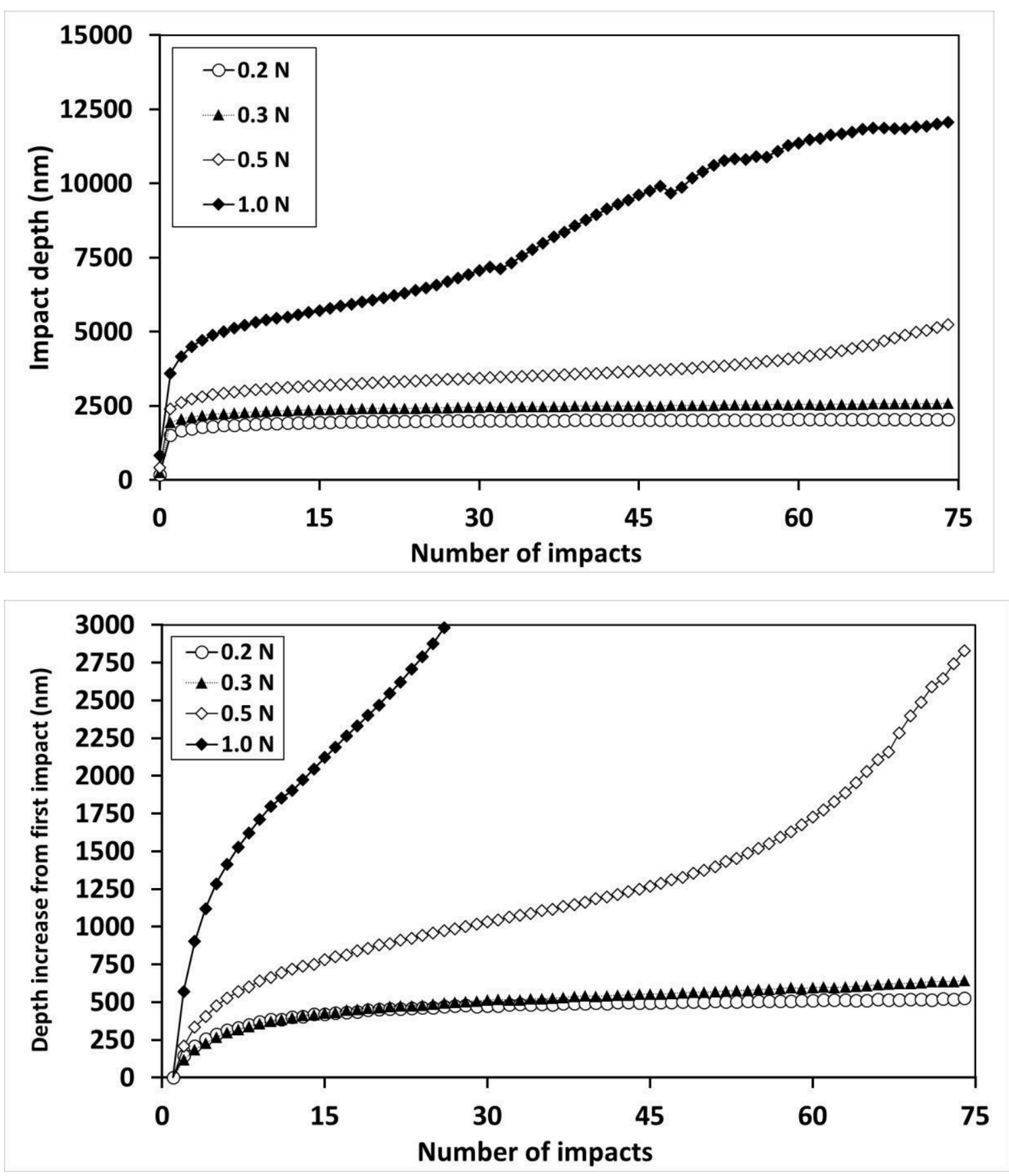

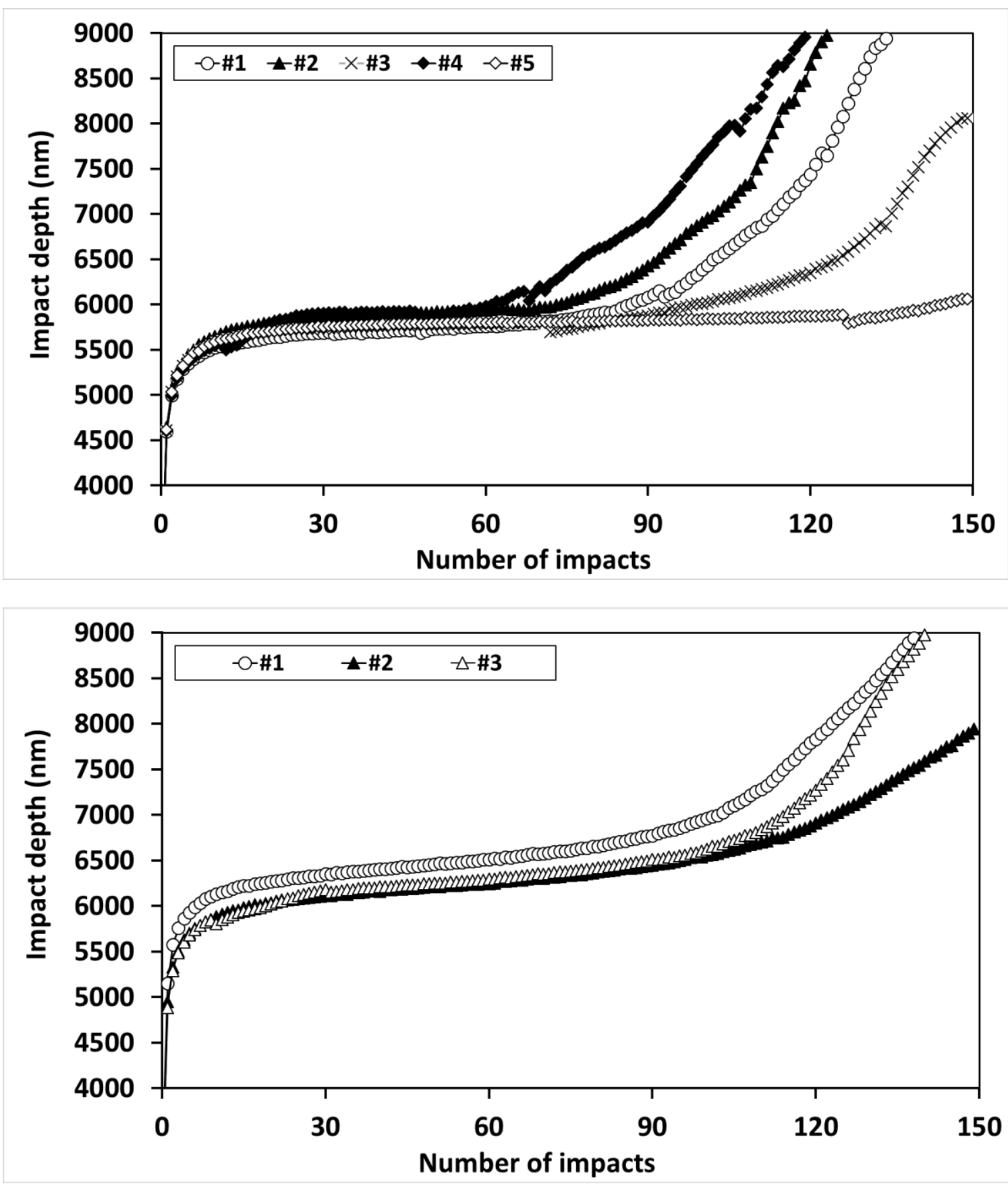
2020-05-25

\section{Probe geometry and surface roughness} effects in microscale impact testing of WC-Co

Beake, Ben D.

Taylor \& Francis

Beake BD, Isern L, Harris AJ, Endrino JL. (2020) Probe geometry and surface roughness effects in microscale impact testing of WC-Co. Materials and Manufacturing Processes, Volume 35, Issue 7, 2020, pp. 836-844

https://doi.org/10.1080/10426914.2020.1740250

Downloaded from Cranfield Library Services E-Repository 